\title{
A produção de conhecimento sobre Conselhos dos Direitos da Criança e do Adolescente no Brasil
}

\section{The knowledge's production about Rights' Councils of Children and Adolescents in Brazil}

\author{
Aline Elisa Maretto Lang*
}

\begin{abstract}
Resumo: O objetivo deste artigo é identificar a produção acadêmica sobre Conselhos dos Direitos da Criança e do Adolescente. Envolveu pesquisa no banco de dados da Scientific Eletronic Library Online (Scielo), da Coordenação de Aperfeiçoamento de Pessoal de Nível Superior (CAPES) e na Biblioteca Digital Brasileira de Teses e Dissertações (BDTD). A publicação "Conselhos dos Direitos: desafios teóricos e práticos das experiências de democratização no campo da criança e do adolescente (2012)", também foi utilizada como fonte de investigação. Nas pesquisas, foram identificadas 20 teses/dissertações e 06 artigos. Com as análises, observamos um aumento na produção de teses e dissertações a partir dos anos 2000, sendo a maioria delas defendida na região sudeste do Brasil. O principal foco de análise dos trabalhos é a atuação dos Conselhos dos Direitos de acordo com suas atribuições, como por exemplo, na elaboração e financiamento de políticas públicas para crianças e adolescentes.
\end{abstract}

Palavras-chave: Conselhos dos Direitos. Controle Social. Criança e Adolescente.

\begin{abstract}
The aim of this article is to identify the academic scope's production about the Right Councils of Children and Adolescents. This article involved researches in the database of Scientific Electronic Library Online (Scielo), Coordination of Improvement Personnel of Higher Education and Brazilian Digital Library of Theses and Dissertations. The publication "Rights' Councils: theoretical and practical's challenges of democratization's experience in children and adolescent's issue (2012)", also it was used as source of research. In this researches, were identified 20 theses/dissertations and 06 articles. Thereafter, in the analysis, can be observed that the production of theses and dissertations has increased from 2000 s and most of them were defended in region southeastern Brazil. The main focus of analysis of the work is the acting of the Councils of Rights in accordance with their assignments, for example in the development and financing of the public policies for children and adolescents.
\end{abstract}

Keywords: Rights' Councils. Social Control. Children and Adolescents.

Recebido em: 10/02/2015. Aceito em: 23/06/2015

"Assistente social, mestre em política social pela Universidade Federal do Espírito Santo. Professora voluntária na Universidade Federal do Espírito Santo, Vitória - ES. E-mail: alinelisa_lang@hotmail.com. 


\section{Introdução}

Historicamente, as ações voltadas para o público infanto-juvenil estiveram restritas às elites ou a tecnocratas, que não se preocupavam em formular uma política de direitos universais (MELIM, 2006). A atenção à criança e ao adolescente sempre priorizou pela necessidade de controle da população pobre. Foram atribuídas a esse segmento geracional diversas formas de tratamento e cujas visões repercutem até a contemporaneidade.

Durante muito tempo, a população pobre e, especialmente as crianças e adolescentes pobres, foram objetos de maior atenção e intervenção do Estado, dos filantropos, médicos, higienistas, educadores, etc. (MELIM, 2006). No Brasil, segundo Pilotti \& Rizzini (2009), não foi diferente: também existiu a necessidade de controle da população pobre, entendida como perigosa. "Impuseram-se reiteradamente propostas assistenciais, destinadas a compensar a ausência de uma política social efetiva, capaz de proporcionar condições equitativas de desenvolvimento para crianças e adolescentes de qualquer natureza" (PILOTTI; RIZZINI, 2009, p. 17).

Esse contexto, somente passou a sofre modificações "[...] com o processo de derrocada do regime militar, quando, paulatinamente, a infância e adolescência passaram a fazer parte da agenda da luta por direitos na sociedade brasileira" (MELIM, 2006, p. 125). Ou seja, no momento em que as políticas para a infância começaram a ser apreendidas enquanto garantia de direitos universais, pois a percepção e prática vigentes até então já não davam resposta à realidade (FALEIROS, 2009): o - atualmente extinto Código de Menores (1979) passou a ser intensamente questionado pelas organizações e movimentos da sociedade civil (CARVALHO, 2009).

Decorrido décadas de políticas assistencialistas e repressivas de atendimento à criança e ao adolescente, no Brasil dos anos 1980/1990, enfim a questão da infância e da juventude obteve uma concepção vinculada à cidadania (CARVALHO, 2009). A vinda da Assembleia Nacional Constituinte configurou-se em uma ótima oportunidade para mudar o quadro desejado: o povo não aguentava mais o processo de alijamento social e econômico, sob o qual foram construídas as ações do Estado (SOUZA, 2009); a população almejava participar e não ficar mais somente na condição de espectador ${ }^{1}$.

No final da década de 1980, esse processo alcançou, enfim, os objetivos em torno dos quais havia se materializado. Após a exposição de duas emendas de caráter popular, "Criança Prioridade Nacional" e "Criança e Constituinte", foram regulamentados os artigos 204 e 227 da Constituição Brasileira, que tiveram seus princípios reafirmados com a aprovação do Estatuto da Criança e do Adolescente - ECA (COSTA, 1993). Inaugurava-se a "doutrina de proteção integral" enquanto desmoronava a "doutrina da situação irregular' (VOGEL, 2009).

O artigo 227 da Constituição (1988) refere-se aos direitos da criança e do adolescente - como dever da família, da sociedade e do Estado -, além de garantir sua absoluta prioridade. Tem-se também o artigo 204 responsável por estabelecer uma nova diretriz referente às ações governamentais, ao definir a participação da população, através de organizações representativas, na formulação das políticas e no controle das ações em todos os níveis (BRASIL, 1988). Tal artigo possibilita, assim, a materialização de uma nova institucionalidade de "[...] fortalecimento da capacidade decisória das instâncias subnacionais - estados e municípios -, ao contrário da trajetória histórica das políticas sociais brasileiras, que, desde 1930, tiveram uma gestão centralizada pelo governo federal" (SOUZA, 2009, p. 177).

A nova legislação configurou-se como diretrizes gerais para a política de atendimento aos direitos da criança e do adolescente, de acordo com o que consta na Constituição Federal de 1988. A descentralização do centro decisório do poder passou a ser um elemento essencial na conquista da democracia participativa. Tais mudanças agregaram ao contexto político do país um novo modelo de exercício da cidadania, que abarca o poder da população de influenciar e controlar as decisões governamentais (BRASIL, 2006). Lançaram-se, assim, os princípios que

\footnotetext{
${ }^{1}$ Sobre a participação da sociedade civil no processo de democratização no Brasil ver "DAGNINO, Evelina (org.). Sociedade Civil e Espaços Públicos no Brasil, São Paulo: Paz e Terra, 2002.".
} 
permitiram a regulamentação do Estatuto da Criança e do Adolescente e, consequentemente, dos Conselhos dos Direitos da Criança e do Adolescente.

O Estatuto da Criança e do Adolescente, Lei 8.069 de 1990, regulamenta as conquistas obtidas em favor do público infanto-juvenil, trazendo amplas inovações (BRASIL, 1990). A primeira delas foi a mudança de paradigma: a criança e o adolescente passaram a ser considerados sujeitos de direitos. A doutrina preconizada pelo Estatuto afirmou o valor da criança e do adolescente como ser humano (COSTA, 1993).

O ECA, em consonância com o previsto na Constituição, inovou também na política de promoção e na de defesa de direitos. Tais inovações refletiram basicamente em três categorias de mudanças: mudanças de conteúdo, mudanças de método e mudanças de gestão (COSTA, 1993). Cabe-nos aqui destacar, a mudança de gestão que interfere na relação entre Estado e Sociedade.

A revisão da relação entre Estado e sociedade consagrou a participação da população - mecanismo já previsto pela Constituição - por meio dos Conselhos Tutelares e dos Conselhos dos Direitos, instâncias regulamentadas pelo Estatuto. Mais do que símbolos da democracia, esses mecanismos passaram a propiciar, de fato, a ação popular no âmbito governamental público (SILVA, 2005). A partir dos Conselhos dos Direitos, a sociedade passou a contar com um legitimo e importante instrumento de participação popular.

Os Conselhos dos Direitos da Criança e do Adolescente são instrumentos que tem sob sua responsabilidade a formulação das diretrizes da política de atendimento aos direitos do público infanto-juvenil, assim como pelo acompanhamento, controle social e avaliação dos programas e ações desenvolvidas (BRASIL, 2006). Conforme preconizado pelo ECA em seu artigo 88 , inciso II, as três esferas governamentais - federal, estadual e municipal - precisam criar seus Conselhos, que deverão ser compostos paritariamente por membros do governo e por segmentos organizados da sociedade civil (BRASIL, 1990). Assim, existem o Conselho Nacional dos Direitos da Criança e do Adolescente (CONANDA), os Conselhos Estaduais e, em âmbito municipal, os Conselhos Municipais dos Direitos da Criança e do Adolescente. Uma de suas principais atribuições é garantir a existência e efetividade das políticas direcionadas a crianças e adolescentes, bem como monitorar o funcionamento do Sistema de Garantia de Direitos instituído pelo ECA(BRASIL, 2006). Assim, "[...] cabe aos Conselhos garantir a participação nos processos de discussão, deliberação e controle da política integral de atendimento à criança e ao adolescente (BRASIL, 2006, p. 21)".

Infere-se, assim, que o efetivo funcionamento dos Conselhos dos Direitos está intrinsecamente relacionado com a participação popular. A partir de sua instituição e adequada atuação é possível colocar em prática o controle social, considerado uma das principais prerrogativas da democracia participativa. Através dos Conselhos Municipais a população passa a ser ouvida, por meio de seus representantes, e tem a possibilidade de compartilhar as decisões que afetam diretamente a realidade das crianças e dos adolescentes de seu município, evitando que o poder público decida sozinho as prioridades de atenção a esse segmento geracional (BRASIL, 2006).

A partir desta análise, podemos afirmar que a criação dos Conselhos dos Direitos vai além do cumprimento de uma exigência legal, tornando-se um grande desafio para os diversos atores sociais envolvidos com a defesa dos direitos da criança e do adolescente. Desse modo, tornam-se essenciais estudos que abordem essa temática, pois somente assim será possível compreender, mais a fundo, a dinâmica interna de funcionamento desse órgão, a participação política de seus membros, os avanços já vivenciados, seus entraves, desafios e demais questões pertinentes ao tema.

Partindo de tais pressupostos, o presente artigo de revisão tem como objetivo identificar a produção acadêmica sobre Conselhos dos Direitos da Criança e do Adolescente, através de buscas feitas no banco de dados da Scientific Eletronic Library Online (Scielo), da Coordenação de Aperfeiçoamento de Pessoal de Nível Superior (CAPES) e na Biblioteca Digital Brasileira de Teses e Dissertações (BDTD). Tal busca justifica-se pela necessidade de constatar o que já existe produzido sobre o assunto, pontuando os principais temas tratados, a fim de analisar onde existem lacunas no debate, bem como as possibilidades de avanços. 


\section{Trajetória Metodológica}

Adotamos como referência temporal para a realização da presente pesquisa os anos de vigência do Estatuto da Criança e do Adolescente de 1990 a 2012, por ser o período de instituição desta lei e, consequentemente, dos Conselhos dos Direitos da Criança e do Adolescente. Ao adotar tal recorte temporal, teremos a possibilidade de identificar quando iniciou a produção acadêmica sobre esse tema, bem como sua distribuição ao longo destes 22 anos de vigência do Estatuto.

Nossa busca por trabalhos que abordem o tema Conselhos dos Direitos da Criança e do Adolescente pode ser dividida em duas fases. A primeira delas refere-se às pesquisas feitas nos bancos de dados da Scientific Eletronic Library Online (Scielo), Coordenação de Aperfeiçoamento de Pessoal de Nível Superior (CAPES) e na Biblioteca Digital Brasileira de Teses e Dissertações (BDTD), cujo número de trabalhos encontrados foi apenas 10. A segunda fase corresponde a uma nova busca feita no portal de periódicos da CAPES a partir de informações obtidas na publicação "Conselhos dos Direitos: desafios teóricos e práticos das experiências de democratização no campo da criança e do adolescente (2012) ${ }^{2 \prime}$.

Na primeira fase da nossa pesquisa, utilizamos como fonte principal a BDTD, os portais de periódicos da Scielo e da CAPES. Os descritos utilizados foram: controle social; criança e adolescente, pois partimos da perspectiva que os Conselhos dos Direitos consistem em um mecanismo de controle social ${ }^{3}$ e, dentre os diversos conselhos existentes, o nosso interesse é especificamente pelo dos Direitos da Criança e do Adolescente. Após a pesquisa, realizamos uma triagem identificando quais trabalhos estavam diretamente relacionados ao tema pesquisado. Posteriormente, organizamos uma lista com todos os trabalhos, indicando título, autor,

\footnotetext{
${ }^{2}$ Esta publicação é resultado de convênio entre a Secretaria de Direitos Humanos da Presidência da República e a Fundação de Apoio e Desenvolvimento ao Ensino, Pesquisa e Extenção (FADEPE/JF), Juiz de Fora - MG, 2012.

${ }^{3} \mathrm{Na}$ Constituição Federal de 1988 a expressão "controle social" é utilizada para indicar a participação da população na elaboração e fiscalização de políticas públicas.
}

instituição de ensino e ano. Nesse momento, interessava-nos saber quando, onde, quem havia pesquisado Conselhos dos Direitos da Criança e do Adolescente, bem como o que havia sido pesquisado.

A partir das buscas realizadas no BDTD foram encontradas 820 dissertações, destas apenas 500 poderiam ser visualizadas. Após a leitura dos títulos e dos resumos, restaram apenas 09 dissertações que abordavam os Conselhos dos Direitos da Criança e do Adolescente, as demais, apareceram no levantamento, pois se relacionavam a temas referentes à criança $e$ ao adolescente.

Na pesquisa feita no site da Scielo, utilizando os mesmos descritores, foram localizados 07 artigos, destes, apenas 01 abordava o tema pesquisado. Já no portal de periódicos da CAPES foram encontrados 170 artigos, após a leitura dos resumos, identificamos que somente 01 fazia uma abordagem sobre Conselhos dos Direitos da Criança e do Adolescente, sendo que este era o mesmo artigo também publicado na Scielo. Assim, ao fim da primeira fase, tivemos acesso a 09 dissertações e 01 artigo.

Passada essa primeira fase das nossas buscas, quando a análise do material encontrado já havia começado, tivemos acesso à publicação "Conselhos dos Direitos: desafios teóricos e práticos das experiências de democratização no campo da criança e do adolescente (2012)" que nos mostrou que nossas pesquisas haviam identificado apenas uma parte do que foi produzido sobre o assunto. Diante disso, adentramos a segunda fase da nossa pesquisa que buscou os trabalhos que ainda não havíamos encontrado, mas que sabíamos que existiam. A fonte de pesquisa e os descritores utilizados foram os mesmos usados para a realização da pesquisa feita para a publicação mencionada, sendo eles: a fonte de pesquisa o Banco de Teses e Dissertações da CAPES; e os descritores: "conselhos de direitos", "conselhos de direitos da criança e do adolescente", "conselheiros de direitos da criança e do adolescente", "conselheiros de direitos" e "conselhos gestores". Nesse momento, foram identificados cerca de 700 trabalhos - somando o resultado das buscas feitas com os diferentes descritores. Destes, apenas 04 deles referiam-se ao tema Conselhos dos Direitos da Criança e do Adolescente, sendo que um deles já havia sido 
encontrado na busca da primeira fase. Assim, apenas 03 novos trabalhos foram descobertos.

Nesta nova busca outros trabalhos foram encontrados, porém ainda não conseguimos identificar o mesmo número de dissertações e teses que a publicação sobre os Conselhos dos Direitos afirma existir. Assim, optamos por examinar ao longo desta obra e em suas referências bibliográficas quais foram os trabalhos por eles utilizados, a fim de conferir quais deles ainda não foram encontrados, bem como aqueles que já tinham aparecido em nossas buscas. Neste levantamento, foram localizados 11 novos trabalhos acadêmicos e 04 que nós já havíamos encontrado na primeira fase da pesquisa. Além disso, nessa publicação, também tivemos acesso a 02 novos artigos. Diante disso, no término da segunda fase da pesquisa, foram identificados 11 trabalhos acadêmicos e 05 artigos.

O resultado final destas buscas foram 20 trabalhos em nível de pós-graduação stricto sensu e 06 artigos publicados em periódicos. Como identificamos alguns trabalhos a partir de referências bibliográficas, foi preciso fazer uma busca na internet do conteúdo completo destas 20 teses/dissertações, porém, tivemos acesso apenas a 14 delas, nas demais só foi possível acessar seus dados básicos como título, autor, instituição e ano de defesa.

Após as pesquisas fizemos, inicialmente, um exame quantitativo dos dados encontrados elencando algumas categorias de análise a fim de obter um panorama geral da produção de trabalhos acadêmicos sobre os Conselhos dos Direitos da Criança e do Adolescente e fazer um exame comparativo com os resultados apresentados na publicação citada anteriormente. $O$ passo seguinte consistiu na leitura dos resumos e dos sumários dos materiais que tivemos acesso e que foram selecionamos após a triagem, realizando uma análise qualitativa dos dados obtidos. Por fim, concluímos nosso trabalho com algumas considerações a respeito das discussões e reflexões realizadas.

\section{Análise da produção de conhecimento em torno dos conselhos dos direitos da criança e do adolescente a partir de teses e dissertações}

Nossa análise da produção do conhecimento acerca dos Conselhos dos Direitos da Criança e do Adolescente inicia-se a partir de um exame quantitativo dos dados obtidos em nossa pesquisa. Para isso optamos por elencar algumas categorias que nos ajudaram a ter um panorama geral a respeito dessa produção teórica. Assim, as reflexões que seguem serão realizadas a partir das seguintes categorias: modalidades de curso de pós-graduação, distribuição temporal, natureza administrativa das instituições de ensino superior, distribuição geográfica das instituições, unidade/ área de conhecimento dos trabalhos e eixos temáticos de análises. Posteriormente realizamos uma análise qualitativa dos trabalhos acadêmicos identificados em nossas pesquisas.

Ao avaliar a distribuição dos 20 trabalhos encontrados por modalidade de curso de pós-graduação stricto sensu, verificou-se que 18 deles foram defendidos em nível de mestrado e apenas 02 correspondem a teses de doutorado. Estes dados corroboram com os resultados apresentados na publicação sobre os Conselhos dos Direitos, que concluiu haver um predomínio de dissertações produzidas em nível de mestrado acadêmico, pois dos 67 trabalhos identificados 55 foram elaborados nessa modalidade, $02 \mathrm{em}$ nível de mestrado profissionalizante e 10 em doutorados (SANTOS; TEIXEIRENSE; LIMA, 2012). O número maior de dissertações é um reflexo da distribuição por nível dos programas de pós-graduação no Brasil. De acordo com o Sistema de Informação Georreferenciadas da CAPES (GEOCAPES) ${ }^{4}$, no ano de 2013 , dos programas que constam na base de dados da CAPES, 1213 eram em nível de mestrado, 469 de mestrado profissionalizante e apenas 54 doutorados.

Quanto à distribuição temporal das teses e dissertações adotamos como critério o ano em que elas foram defendidas. Nessa análise a publicação sobre os Conselhos dos Direitos verificou que a produção nessa área temática vem mantendo movimentos bastante variáveis

\footnotetext{
${ }^{4}$ Dados disponíveis para download no site: www.geocapes.capes.gov.br
} 
no período por eles considerado (1992 a 2009). Além disso, os autores identificaram que o primeiro trabalho acadêmico sobre essa temática no país foi uma dissertação defendida em $1992^{5}$ (SANTOS; TEIXEIRENSE; LIMA, 2012). Na análise de nossa amostra pudemos identificar que a maior parte dos trabalhos foram realizados na segunda década após a promulgação do ECA. Dos 20 trabalhos acadêmicos estudados, apenas um foi defendido na década de 1990, os demais foram defendidos entre os anos 2000 e 2011, sendo que a maioria deles também foi produzido no ano de 2009 (05 deles). Cabe ressaltar, que os dois trabalhos defendidos em 2011 não constam na publicação citada anteriormente, pois o recorte temporal desta pesquisa abrangeu apenas os trabalhos realizados até 2010 .

As instituições públicas de ensino superior foram as responsáveis pelo maior número de teses e dissertações produzidas. Do universo de 20 trabalhos, 16 deles foram realizados em universidades públicas e apenas 04 em instituições particulares. Cabe destacar, também, que das 16 teses/dissertações defendidas em instituições públicas 11 foram em nível federal e 05 em universidades estaduais. Esses dados também são compatíveis com os resultados já apresentados na publicação sobre os Conselhos dos Direitos que igualmente conclui que a maioria dos trabalhos acadêmicos foram produzidos em instituições públicas de ensino superior (SANTOS; TEIXEIRENSE; LIMA, 2012).

Ao analisar a distribuição geográfica das instituições onde as teses e dissertações foram defendidas, verificamos que nosso resultado se distingue em parte do que foi apresentado na publicação sobre os Conselhos dos Diretos. Nesta publicação os autores concluíram que a maior parte das teses e dissertações foram defendidas na região Sudeste (16 trabalhos), seguido da região Sul (09 trabalhos), região Nordeste (06 trabaIhos), região Centro-Oeste (02 trabalhos) e região Norte (01 trabalho) (SANTOS; TEIXEIRENSE; LIMA, 2012). Essa concentração de publicações na região Sudeste ocorre, pois é nessa região que estão localizados grande parte dos programas

\footnotetext{
${ }^{5}$ A dissertação indicada é de autoria de Felício de Araújo Pontes Júnior e foi intitulada "O Conselho de Direitos da Criança e do Adolescente: uma modalidade de exercício dos direitos de participação política: fatores determinantes e modos de atuação".
}

de pós-graduação no Brasil. De acordo com o Sistema de Informações Georreferenciadas da CAPES mais de $45 \%$ dos cursos de pós-graduação no Brasil estão sediados na região Sudeste.

Do mesmo modo, também verificamos que a maior parte da nossa amostra foi produzida em instituições situadas na região Sudeste (13 trabalhos), principalmente na região metropolitana de São Paulo. Porém, chamou-nos atenção o fato de, nesse universo de pesquisa, não conter nenhum trabalho que tenha sido produzido na região Nordeste do país, diferentemente do que foi observado na publicação sobre os Conselhos dos Direitos em que o Nordeste é a terceira região brasileira que mais produziu trabalhos acadêmicos nesse campo de pesquisa. Esse dado pode nos indicar que embora a região Nordeste tenha pesquisado essa temática, esses resultados não têm sido amplamente divulgados, pois não conseguidos ter acesso a nenhum deles.

Os dados básicos dos 20 trabalhos utilizados não permitiam um exame em relação a sua unidade/área de conhecimento. Diante disso, a análise dessa categoria ficou restrita aos 14 trabalhos que foram acessados integralmente. Conclui-se a partir desta apreciação que existem diferentes áreas de conhecimento se dispondo a pesquisar o tema Conselhos dos Direitos da Criança e do Adolescente. O maior número de teses/dissertações é realizado em programas de pós-graduação na área de Serviço Social (05 trabalhos), em seguida, têm-se trabalhos produzidos nos programas na área de Política Social e Administração ambos com 03 trabaIhos; e Ciência da Informação, Ciências Sociais e Economia Doméstica com 01 trabalho defendido por cada uma. Tais dados revelam que existe uma variedade substantiva de "cursos" que vem se dedicando ao estudo dos Conselhos dos Direitos (SANTOS; TEIXEIRENSE; LIMA, 2012).

Do mesmo modo, os eixos temáticos de análises sobre os Conselhos dos Direitos da Criança e do adolescente, também foram examinados apenas nos 14 trabalhos que foram acessados integralmente. A maioria das teses e dissertações estudadas fazem uma abordagem sobre a história da infância e da juventude no Brasil, políticas sociais e a origem do ECA. Outro assunto recorrente é a mudança na relação entre - Estado e a Sociedade Civil a partir do processo de democratização no Brasil. A democracia 
também é um assunto muito lembrado nas discussões feitas nestes trabalhos acadêmicos. Findada a análise quantitativa dos dados coletados, nossos estudos adentraram em uma nova fase. Agora, interessa-nos considerar o que os pesquisadores têm discutido em seus trabalhos, buscando identificar quais foram os principais objetivos, resultados, desafios, contexto em que estão inseridos, características comuns aos Conselhos pesquisados, dentre outros assuntos que foram abordados nas teses e dissertações estudadas.

Inicialmente, com análise dos trabalhos obtidos em nossa pesquisa, chamou nossa atenção o fato de que dos 14 autores, 09 deles se preocuparam em fazer uma abordagem descrevendo a trajetória da Política de Atenção a Criança e ao Adolescente no Brasil e/ou do ECA em algum momento ao longo do trabalho. Essa discussão é feita com intuito de demonstrar que, historicamente, a criança e o adolescente nem sempre foram vistos como sujeitos de direitos; e que para chegar à legislação que temos em vigor, um longo percurso foi percorrido.

Nos trabalhos utilizados como referencial teórico para a construção deste artigo, os autores fazem o resgate histórico da política de assistência à criança e ao adolescente a partir de diferentes períodos e marcos histórico. Porém, a maioria deles procura evidenciar, de formas diversas, que "a história social e cultural que marca o mundo ocidental e, em particular, o Brasil, não apresenta um passado de glórias em relação ao modo de pensar e agir no que diz respeito à atenção às crianças e aos adolescentes" (MELIM, 2006, p. 105). As dissertações e teses analisadas demonstram que a trajetória brasileira de atenção à criança e ao adolescente sempre priorizou pelo controle da população pobre.

Os nove autores que fazem essa análise deixam claro que o confinamento de crianças e adolescentes pobres em instituições asilares foi uma prática constante no país, essas ações eram muitas vezes realizadas pelas instituições filantrópicas e apoiadas pelo Estado. Somado a isto, as ações direcionadas a este segmento geracional eram realizadas pela polícia e contavam com o apoio dos juízes que se pautavam nas legislações vigentes (MARCHESI, 2008).
Outro fato que merece destaque é que, de acordo com o contexto histórico, político e econômico de cada época, a política de assistência direcionada ao público infanto-juvenil vai, a cada novo regime político, ser direcionada em conformidade com o interesse do bloco econômico dominante que esta no poder (MARCHESI, 2008).

Diante da história da política de atendimento a criança e ao adolescente resgatada pelos pesquisadores, Melim (2006, p. 125) conclui que

[...] algumas características que marcaram a história das políticas sociais brasileiras relativas à infância e à adolescência, em que predominava como produção simbólica a respeito dos indivíduos dessas faixas etárias a concepção segundo a qual se tratava de delinqüentes e abandonados. Destacase a criminalização da pobreza - a criança pobre era tida como um futuro marginal em potencial e, por isso, era preciso reprimi-la e corrigi-la pela violência. As práticas de internação eram priorizadas e a força de trabalho era tida como único bem que a criança pobre possuía. Logo, nessas instituições, crianças e adolescentes eram submetidos ao trabalho forçado. As ações foram, historicamente, marcadas pela ênfase na esfera privada e no recuo das funções públicas do Estado. Quando este passa a ter um papel mais marcante nessa área, reforça as ações compensatórias e não-preventivas, centralizando a formulação das políticas na esfera federal de governo. $O$ assistencialismo evidenciava a clara segmentação da população e a não-cidadania das crianças pobres.

Depois de percorrido esse percurso histórico até a promulgação do Estatuto da Criança e do Adolescente em 1990, os autores elucidam sobre as mudanças trazidas por essa nova legislação em vigor. Nesse sentido, alguns pontos são comuns aos trabalhos, tendo em vista que a maioria das dissertações/teses utiliza o autor Antônio Carlos Gomes da Costa (1993) para fazer essa reflexão.

Para Costa (1993), o Estatuto introduzirá algumas mudanças no conteúdo, no método e na gestão das ações destinadas a criança e ao adolescente. Para ele, as mudanças de conteúdo referem-se ao acréscimo de novos direitos para a infância e juventude, envolvendo tanto os direitos individuais, quanto os coletivos. A mudança de método, segundo Costa (1993, p. 21), "[...] aponta 
na direção da superação do assistencialismo como princípio definidor das relações entre os pobres e o ramo social do Estado, ou seja, as políticas e programas governamentais voltados para o atendimento de suas necessidades".

O ECA, em consonância com a Constituição Federal de 1988, proporciona mudanças no campo da gestão ao estabelecer dois princípios básicos para a política de atendimento à infância e à adolescência: a descentralização político-administrativa e a participação da população por meio de suas organizações representativas. O Estatuto proporciona uma nova relação do trabalho social entre União, estados e municípios, dando maior autonomia aos municípios para implementar e executar suas políticas (MARCHESI, 2008).

É nesse momento, ao abordar as mudanças na gestão trazidas pelo ECA, que os autores introduzem a ideia dos Conselhos dos Direitos da Criança e do Adolescente. Ao fazer referência à participação da população na formulação e fiscalização das políticas sociais, tanto a Constituição quanto o Estatuto possibilitam a criação dos conselhos gestores de políticas públicas, o que, no caso da criança e do adolescente, corresponde aos Conselhos dos Direitos da Criança e do Adolescente.

Agora, pela Constituição e o Estatuto, a cidadania organizada está convocada a participar em instâncias até aqui privativas dos homens públicos, dos dirigentes de políticas, dos chamados homens de Estado, como a formulação das políticas e o controle das ações em todos os níveis (COSTA, 1993, p. 41).

Após o resgate histórico da política social destinada ao público infanto-juvenil, os pesquisadores, da amostra aqui analisada, se apropriam de conteúdos teóricos que possibilitam a compreensão e análise do contexto no qual os Conselhos dos Direitos estão inseridos. Nesse momento, a maioria dos autores faz uma exposição das analises por eles alcançadas a partir das pesquisas realizadas, que se diferem de acordo com os objetivos de cada pesquisador. É a partir dos aspectos marcantes destas analises que damos continuidade as nossas reflexões.

Ao expor um balanço da produção bibliográfica acerca do Conselho dos Direitos da Criança e do Adolescente, Mirla Cisne (2012) faz uma apresentação a partir de três eixos: os principais objetivos, resultados e desafios apresentados pelos autores das teses e dissertações de seu universo de pesquisa.

Nesse sentido, Cisne (2012) conclui que os principais objetivos exibidos nos trabalhos acadêmicos examinados foram analisar:

Sua práxis; o seu potencial democrático; as relações de poder nas decisões; a representação paritária entre os conselheiros; as concepções e a atuação dos conselheiros; a influência nas políticas públicas voltadas para a infância e para a adolescência; os incentivos institucionais; as parcerias e as possibilidades de participação e controle social na gestão pública (CISNE, 2012, p. 41).

Quanto aos principais resultados alcançados pelos autores, Cisne (2012) destaca que foram a:

[...] fragilidade na formação dos conselheiros representantes da sociedade civil; prevalência de posturas autoritárias e clientelismo no trato da coisa pública; ausência de uma cultura política de participação que implica em obstáculos no exercício da corresponsabilidade dos Conselhos na gestão da coisa pública; não efetivação da paridade entre seus membros; ingerência do poder público em detrimento da representação dos interesses da sociedade civil; falta de recursos e investimentos públicos; dificuldade de garantir que as ações dos conselheiros imputem decisões, em especial, aqueles que representam a sociedade civil (CISNE, 2012, p. 41).

Os Conselhos aparecem, na maioria das vezes, como "[...] um espaço de ações repetitivas com uma prática cotidiana de burocracias, que não conseguem provocar alterações nas políticas voltadas para crianças e adolescentes (CLAUDINO, 2007, p. 155)". Diante disso, a autora lembra que é preciso análises que tragam para a discussão o contexto político em que os Conselhos estão inseridos, para não cometer o erro da culpabilização dos conselheiros (CLAUDINO, 2007). Nesse sentido, o neoliberalismo foi apresentado em muitos trabalhos como um aspecto fundamental para a análise deste contexto político no qual os Conselhos encontram-se inseridos.

As chamadas políticas de ajuste neoliberal fazem parte de um movimento de ajuste global 
no sentido da globalização financeira e produtiva. Tais políticas foram consagradas no chamado Consenso de Washington. O Brasil, como um país inserido nesse contexto globalizante, não ficou isento às consequências do neoliberalismo (SILVA, 2011). Nesse contexto, estabeleceram-se fortes cortes referentes ao financiamento das políticas sociais, visto como uma medida necessária para que o país diminuísse gastos. Assim, a partir da década de 1990 o Brasil passa a assumir atitudes que irão caracterizá-lo como um Estado Mínimo (MARCHESI, 2008).

Uma das consequências dessa política neoliberal foi um forte apelo para a filantropia e para a desresponsabilização do Estado em relação às políticas sociais, tendo como um de seus desdobramentos as parcerias entre o público e o privado (CISNE, 2012). Sobre essas parcerias, identificamos uma tese que analisou essa relação em torno dos Conselhos dos Direitos da Criança e do Adolescente. Nesse trabalho, a autora faz um alerta em sua conclusão sobre os riscos dos incentivos fiscais em relação à responsabilidade social das empresas, concluindo que

Este incentivo, aliado a difusão da responsabilidade social das empresas, contribui [...] para que empresas passem a influenciar essa instância, pois os agentes empresariais tendem neste cenário a associar a ação de doação à ideia de investimento social, monitorando a aplicação desses recursos (BARBOSA, 2009, p.128)

Cisne (2012) destaca, também, que embora existam as particularidades locais de cada Conselho, existem características comuns entre eles que são advindas da cultura política nacional. Ao estabelecer uma discussão sobre os espaços democráticos legitimados pela Constituição Federal de 1988, a maioria das teses/dissertações aborda, direta ou indiretamente, a ditadura militar, pois, ao analisarem a organização social deste período, verifica-se que o autoritarismo que caracterizou esse modelo de gestão estatal exerceu influência sobre as ações dos governos que o sucederam no que se refere à administração da coisa pública (ANHUCCI, 2007).

Os autores também observam que a pouca participação política do cidadão brasileiro é resultado da organização de uma estrutura social que, historicamente, sustentou a população afastada dos processos de tomadas de decisões de interesse público, impedindo que ocorressem processos verdadeiramente democráticos (ANHUCCI, 2007).

A partir desta perspectiva, nas teses/dissertações consideradas são destacados o papel da sociedade civil no que tange o processo de abertura política. Pode-se afirmar que a Constituição Federal de 1988 instituiu uma nova relação entre Estado e a Sociedade civil, ou seja, permitiu a abertura de espaços de participação popular onde a sociedade civil organizada poderá exercer um maior controle e também debater junto ao Estado a respeito das ações realizadas (MARCHESI, 2008).

Nesse sentido, quatro autores trazem para o debate o fato de que durante o decurso da história política do Brasil, a sociedade civil esteve impedida de participar com vigor do processo de discussão e protagonismo político. Existia um Estado caracterizado por governos autoritários, populistas e clientelistas. Desse modo, erguer um espaço democrático no interior dos espaços institucionalmente criados pelo Estado não é tarefa fácil. "Perpassa por um extenso processo de amadurecimento político, do desenvolvimento de uma cultura política capaz de ser critica, propositiva e que tenha nesses espaços um lugar privilegiado de negociação de interesses coletivos, universais (MARCHESI, 2008, p. 35)".

Os Conselhos dos Direitos constituem um desses espaços públicos de interlocução entre Estado e sociedade civil, instituídos a partir da Constituição de 1988. Sendo assim, é fundamental estabelecer um debate a respeito da inserção da sociedade civil nesses espaços e de como ela tem compreendido sua função na defesa e ampliação da democracia participativa (MARCHESI, 2008).

Nos resultados apresentados pelos pesquisadores, é possível perceber que apesar das conquistas democráticas obtidas com a Constituição Federal de 1988, e, nesse caso especialmente, com a instituição dos Conselhos dos Direitos da Criança e do Adolescente, temos ainda um longo caminho a percorrer para conquistar a efetivação completa de sua proposta (CISNE, 2012). Nesse sentido, Marchesi (2008) destaca que

[...] a efetivação do Conselho de Direitos, enquanto um instrumento de interlocução entre 
poder público e sociedade civil na construção e fortalecimento de uma participação política, bem como na defesa do interesse da criança e do adolescente, pensada de forma coletiva, ainda não completou a sua maioridade política. A dimensão política, da participação mais ampliada, tem ficado muito aquém do esperado (p.116).

Apesar de todas as limitações e dificuldades apresentadas nos trabalhos científicos investigados, existe também um reconhecimento da maioria dos autores da importância dos Conselhos dos Direitos da Criança e do Adolescente, na medida em que eles o percebem como um avanço e uma conquista democrática (CISNE, 2012). Sobre esse aspecto, em suas considerações finais, Publio (2009, p. 103) conclui que o Conselho Municipal dos Direitos da Criança e do Adolescente "como a maioria das esferas colegiadas, é um espaço de conflitos e resistências, de interesses individuais e coletivos, mas, principalmente, é um ambiente ideal para se aprimorar o exercício da democracia participativa".

A partir das análises das teses e dissertações de seu universo de pesquisa, Cisne (2012) afirma que os principais desafios para os Conselhos dos Direitos da Criança e do Adolescente se tornarem, efetivamente, um espaço de formulação, deliberação e controle das políticas públicas direcionadas a esse seguimento geracional foram a:

[...] garantia de uma formação continuada para os conselheiros, de forma a possibilitar uma intervenção qualificada, sintonizada com o papel político dos conselhos; ruptura com a política clientelista, populista e autoritária existente no país; investimento estatal nas políticas sociais voltadas para o público infanto-juvenil; autonomia e poder de decisão e a politização da sociedade civil (CISNE, 2012, p. 44).

Apesar de cada trabalho científico apresentar um objetivo especifico, de estarem inseridos em contextos diversos e de cada Conselho apresentar características particulares, ao fim do exame das diferentes teses/dissertações, do universo desta pesquisa, é importante ressaltar que os resultados apresentados estão dialeticamente relacionados, ou seja, eles possuem determinações comuns como o fato de estarem inseridos em uma sociedade solidificada em bases antidemocráticas, permeada pelo populismo e pelo clientelismo.

\section{Considerações Finais}

Os dados obtidos na pesquisa revelam que a produção acadêmica sobre os Conselhos dos Direitos da Criança e do Adolescente vem crescendo, de maneira irregular, principalmente a partir dos anos 2000. Os estudos sobre essa temática tem se concentrado principalmente em nível de mestrado. Chama a atenção o número de trabalhos produzidos na região Sudeste do país, demonstrando que existe uma profunda concentração regional dessa produção. Outro fator relevante observado é a diversidade de "cursos" que vem se dispondo a estudar os Conselhos dos Direitos, como por exemplo, programas vinculados à área de Administração.

Por se tratar de um Conselho com diversas funções, os estudos são bem distintos quanto aos assuntos abordados, no entanto, a maior parte deles não deixa de fazer um resgate histórico das políticas sociais brasileiras destinadas ao público infanto-juvenil, bem como o processo de implementação do Estatuto da Criança e do Adolescente. A relação entre Estado e Sociedade Civil também é muito discutida, assim como a cultura política brasileira e os desafios para a conquista da democracia participativa e os reflexos dessa cultura na atuação dos Conselhos.

As análises dos trabalhos acadêmicos apontam que os Conselhos dos Direitos da Criança e do Adolescente vivenciam desafios diários na busca pela efetivação dos direitos deste segmento geracional e para o seu efetivo funcionamento. Grande parte destas dificuldades são reflexos de uma sociedade desigual, marcada por uma cultura política antidemocrática.

Alguns autores lembram, também, que os Conselhos representam um espaço de conquista para o exercício da democracia participativa e que por isso, a sua concretização como espaço democrático exige uma organização política que ultrapasse a sua organização interna.

A busca e as análises das pesquisas que tiveram como tema de estudo os Conselhos dos Direitos da Criança e do adolescente, nos ajudaram a ter um panorama geral dessa produção em nível nacional. As leituras desses trabalhos 
nos mostraram que, embora o tema venha sendo bastante pesquisado, estes estudos são muito focados em Conselhos específicos, o que nos leva a questionar se esses resultados podem ser generalizados. A falta de análises mais globalizadas pode estar favorecendo a formulação de uma "imagem distorcida" da realidade dos Conselhos dos Direitos, o que indica uma lacuna nesse debate.

O fato de existirem apenas 07 estudos no Brasil que abordem o Conselho Estadual dos Direitos da Criança e do Adolescente (SANTOS; TEIXEIRENSE; LIMA, 2012) é mais um indicador de que existe uma carência de pesquisas que extrapolem a realidade municipal dos Conselhos. Estudos dos Conselhos Estaduais podem indicar o caminho para uma reflexão mais globalizada desse órgão, possibilitando - inclusive - entender como as ações dos Conselhos Estaduais refletem na atuação dos conselheiros municipais dos direitos da criança e do adolescente.

Por fim, cabe destacar que, embora essa temática venha sendo bastante discutida, encontramos dificuldades para acessar os trabalhos acadêmicos produzidos. Somente a partir do acesso a publicação sobre os Conselhos dos Direitos que foi possível termos uma visão mais ampla dessa produção no Brasil.

\section{Referências}

ANHUCCI, Valdir. O Conselho Municipal dos Direitos da Criança e do Adolescente na perspectiva da participação e do controle social. 2007. Dissertação (Mestrado em Serviço Social e Política Social) Universidade Estadual de Londrina, Londrina.

BARBOSA, Maria Nazaré Lins. Fomento empresarial aos conselhos municipais dos direitos da criança e do adolescente. 2009. 165 p. Tese (Doutorado em Administração pública e Governo) - Escola de Administração de Empresas de São Paulo, Fundação Getúlio Vargas, São Paulo, 2009.

BRASIL. Conselho Nacional dos Direitos da Criança e do Adolescente - CONANDA. Conselho Municipal dos Diretos da Criança e do Adolescente e Conselho Tutelar: orientações para criação e funcionamento. Secretaria Especial dos Direitos Humanos. Brasília, 2006.

BRASIL. Constituição da República Federativa do Brasil. Brasília, out. 1988. Presidência da República Federativa do Brasil. Disponível em: <http://www.planalto.gov.br/ccivil_03/constituicao/ constitui\%C3\%A7ao.htm>. Acesso em: 21 ago. 2013.

BRASIL. Lei 8.069. Dispõe sobre o Estatuto da Criança e do Adolescente e dá outras providências. Presidência da República Federativa do Brasil. Brasília, 13 jul. 1990. Disponível em: <http://www. planalto.gov.br/ccivil/LEIS/L8069.htm>. Acesso em: 21 ago 2013.

CARVALHO, Lúcia Abadia de. Conselhos Tutelares (ou tutelados?): a experiência no município de Goiânia. 180 f. 2009. Dissertação (Mestrado em Serviço Social) - Programa de Pós-Graduação stricto sensu em Serviço Social, Universidade Católica de Goiás, 2009.

CISNE, Mirla. A produção do conhecimento em torno dos conselhos dos direitos da criança e do adolescente: uma análise de teses e dissertações. In: FILHO, Rodrigo de Souza; SANTOS, Benedito Rodrigues dos; DURIGUETTO, Maria Lúcia. (Org.). Conselhos dos Direitos: desafios teóricos e práticos das experiências de democratização no campo da criança e do adolescente. Juiz de Fora: Ed. UFJF, 2012. p. 39-49.

CLAUDINO, Selma Cristine. As conferências municipais dos direitos das crianças e dos adolescentes e o potencial deliberativo do CMDCA em questão: quer um conselho. 2007. Dissertação (Mestrado em Serviço Social) - Universidade Federal de Santa Catarina, Florianópolis.

COSTA, Antônio Carlos Gomes da. É possível mudar: a criança, o adolescente e a família na política social do município. São Paulo: Malheiros Editora, 1993.

FALEIROS, Eva Teresinha Silveira, A criança e o adolescente. Objetos sem valor no Brasil Colônia e no Império. In: PILLOTI, Francisco; RIZZINI, Irene (Orgs.). A arte de governar crianças: a história das políticas sociais, da legislação e da assistência à infância no Brasil. $2^{\mathrm{a}}$ ed. revisada. São Paulo: Cortez, 2009. p. $203-222$.

FILHO, Rodrigo de Souza; SANTOS, Benedito Rodrigues dos; DURIGUETTO, Maria Lúcia. (Org.). Conselhos dos Direitos: desafios teóricos e práticos das experiências de democratização no campo da criança e do adolescente. Juiz de Fora: Ed. UFJF, 2012.

MARCHESI, Elisângela Maria. O Conselho dos Direitos da Criança e do Adolescente do município de Cariacica: discutindo as prioridades do financiamento. 2008. 106 p. Dissertação (Mestrado em Política Social) - Programa de Pós-Graduação 
em Política Social, Universidade Federal do Espírito Santo, Vitória, 2008.

PILOTTI, Francisco; RIZZINI, Irene (Orgs.). A arte de governar crianças: a história das políticas sociais, da legislação e da assistência à infância no Brasil. $2^{\mathrm{a}}$ ed. revisada. São Paulo: Cortez, 2009.

PUBLIO, Carlos Alberto Maciel. O conselho municipal dos direitos da criança e do adolescente do município de Vitória da Conquista: um espaço público de exercício da democracia participativa. 2009. 109 p. Dissertação (Mestrado em Ciências Sociais) PUC-SP, São Paulo, 2009.

SANTOS, B.R.; TEIXEIRENSE, I. P.; LIMA, M. L.; Uma breve sociologia das pesquisas de pós-graduação sobre conselhos dos direitos da criança e do adolescente no Brasil. In: FILHO, Rodrigo de Souza; SANTOS, Benedito Rodrigues dos; DURIGUETTO, Maria Lúcia.(Org.). Conselhos dos Direitos: desafios teóricos e práticos das experiências de democratização no campo da criança e do adolescente. Juiz de Fora: Ed. UFJF, 2012. p. 15-35.

SILVA, Lindomar José da. Projeto de capacitação de conselheiros dos direitos: uma análise dos seus impactos nos conselhos dos Direitos da Criança e do Adolescente da Zona da Mata Mineira. 2011. 203 f. Dissertação (Mestrado em Serviço Social) Universidade Federal de Juiz de Fora, Juiz de Fora, 2011.

SILVA, Maria Liduina de Oliveira e. O Estatuto da Criança e do Adolescente e o Código de Menores: continuidades e descontinuidades. In: Revista Serviço Social e Sociedade, $n^{\circ} 83$, ano XXVI. São Paulo: Cortez, 2005. p. 30-48.

SOUZA, Rodriane de Oliveira. Participação e Controle Social. In: LEAL, Maria Cristina; MATOS, Maurílio Castro de; SALES, Mione Apolinário Sales (Orgs.). Política social, família e juventude: uma questão de direitos. $4^{\text {a }}$ ed. São Paulo: Cortez, 2009. p. 167 - 188.

VOGEL, Arno. Do Estado ao Estatuto. Propostas e vicissitudes da política de atendimento à infância e adolescência no Brasil contemporâneo. In: PILLOTI, Francisco; RIZZINI, Irene (Orgs.). A arte de governar crianças: a história das políticas sociais, da legislação e da assistência à infância no Brasil. $2^{\mathrm{a}}$ ed. revisada. São Paulo: Cortez, 2009. p. 287 - 322. 


\begin{tabular}{|c|c|c|c|c|}
\hline \multicolumn{5}{|c|}{ Trabalhos Utilizados como Amostra da Pesquisa } \\
\hline \multicolumn{5}{|c|}{ TESES e DISSERTAÇÕES } \\
\hline No & Título & Autor & Instituição de & $\begin{array}{l}\text { Ano de } \\
\text { Defesa }\end{array}$ \\
\hline \multicolumn{5}{|c|}{ Trabalhos acessados na Integra } \\
\hline 01 & $\begin{array}{l}\text { O conselho de Direitos da Criança e do } \\
\text { Adolescente no município de Cariacica: } \\
\text { Discutindo as prioridades do financiamento }\end{array}$ & $\begin{array}{l}\text { Elisângela Maria } \\
\text { Marchesi }\end{array}$ & UFES & 2008 \\
\hline 02 & $\begin{array}{l}\text { A participação popular no Conselho de } \\
\text { Direitos da criança e do adolescente de } \\
\text { Vitória: promessa ou realidade }\end{array}$ & $\begin{array}{l}\text { Juliana Iglesias } \\
\text { Melim }\end{array}$ & UFES & 2006 \\
\hline 03 & $\begin{array}{l}\text { O conselho de Direitos como espaço para } \\
\text { A articulação de políticas públicas }\end{array}$ & $\begin{array}{l}\text { Franciele Jaqueline } \\
\text { Gregorio }\end{array}$ & UEL & 2010 \\
\hline 04 & $\begin{array}{l}\text { Projeto de capacitação de conselheiros de } \\
\text { Direitos: uma analise de seus impactos nos } \\
\text { conselhos dos direitos da Criança e do } \\
\text { Adolescente da zona da mata mineira }\end{array}$ & $\begin{array}{l}\text { Lindomar José da } \\
\text { Silva }\end{array}$ & UFJF & 2011 \\
\hline 05 & $\begin{array}{l}\text { Política Pública de atendimento à criança } \\
\text { e ao adolescente nas perspectivas dos CMDCA, } \\
\text { CT e famílias }\end{array}$ & $\begin{array}{l}\text { Fabiana Noronha de } \\
\text { Oliveira }\end{array}$ & UFV & 2011 \\
\hline 06 & $\begin{array}{l}\text { O Conselho Municipal dos Direitos da } \\
\text { Criança e do Adolescente na perspectiva da } \\
\text { Participação e do Controle Social }\end{array}$ & Valdir Anhucci & UEL & 2007 \\
\hline 07 & $\begin{array}{l}\text { O percurso da informação no Conselho } \\
\text { Estadual da Criança e do Adolescente: } \\
\text { Atuação, desafios e contradições }\end{array}$ & Ana Paula Silva & UFMG & 2005 \\
\hline 08 & $\begin{array}{l}\text { Parcerias municipais com o terceiro setor: o } \\
\text { Caso do Conselho Municipal dos direitos da } \\
\text { Criança e do Adolescente de Natal }\end{array}$ & $\begin{array}{l}\text { Laysce Rocha de } \\
\text { Moura }\end{array}$ & UFRN & 2009 \\
\hline 09 & $\begin{array}{l}\text { Se conselho fosse bom: reflexões sobre os } \\
\text { Conselhos municipais dos direitos da criança } \\
\text { E do adolescente na Região Norte e Noroeste } \\
\text { Fluminense }\end{array}$ & $\begin{array}{l}\text { Beatriz Mateus } \\
\text { Pereira }\end{array}$ & UENF & 2008 \\
\hline 10 & $\begin{array}{l}\text { Fomento empresarial aos conselhos } \\
\text { Municipais dos direitos da criança e do } \\
\text { Adolescente }\end{array}$ & $\begin{array}{l}\text { Maria Nazaré Lins } \\
\text { Barbosa (tese) }\end{array}$ & FGV & 2009 \\
\hline 11 & $\begin{array}{l}\text { As interfaces das relações de poder nas } \\
\text { Decisões dos conselhos municipais dos } \\
\text { Direitos da criança e do adolescente de } \\
\text { Sorocaba (SP) sobre o fundo municipal dos } \\
\text { Direitos da criança e do adolescente - } 2006 \text { a } \\
2008\end{array}$ & $\begin{array}{l}\text { Carla Jacques } \\
\text { Carlos }\end{array}$ & PUC - SP & 2009 \\
\hline 12 & $\begin{array}{l}\text { As conferencias municipais dos direitos das } \\
\text { Crianças e dos adolescentes e o potencial } \\
\text { Deliberativo do CMDCA em questão: quer } \\
\text { Um conselho }\end{array}$ & $\begin{array}{l}\text { Cristiane Selma } \\
\text { Claudino }\end{array}$ & UFSC & 2007 \\
\hline
\end{tabular}




\begin{tabular}{|c|c|c|c|c|}
\hline \multicolumn{5}{|c|}{ Trabalhos Utilizados como Amostra da Pesquisa } \\
\hline \multicolumn{5}{|c|}{ TESES e DISSERTAÇÕES } \\
\hline No & Título & Autor & Instituição de & $\begin{array}{l}\text { Ano de } \\
\text { Defesa }\end{array}$ \\
\hline \multicolumn{5}{|c|}{ Trabalhos acessados na Integra } \\
\hline 13 & $\begin{array}{l}\text { O Conselho Municipal dos Direitos da } \\
\text { Criança e do Adolescente do município de } \\
\text { Vitória da Conquista: espaço público de } \\
\text { Exercício da democracia participativa }\end{array}$ & $\begin{array}{l}\text { Carlos Alberto } \\
\text { Maciel Publio }\end{array}$ & PUC - SP & 2009 \\
\hline 14 & $\begin{array}{l}\text { Conselhos de Estado como atores estratégicos } \\
\text { Para a cogestão das Políticas Públicas nas } \\
\text { Áreas da Infância e Juventude }\end{array}$ & $\begin{array}{l}\text { Azamor Lopes de } \\
\text { Lucena }\end{array}$ & UFRO & 2009 \\
\hline \multicolumn{5}{|c|}{ Trabalhos acessados apenas pelo Título } \\
\hline 15 & $\begin{array}{l}\text { Os conselhos paritários, o Estado e a } \\
\text { Sociedade civil: possibilidades e limites à } \\
\text { Efetivação da cidadania e ao controle das } \\
\text { Políticas públicas no Brasil }\end{array}$ & $\begin{array}{l}\text { Paulo Afonso de } \\
\text { Araújo Quermes }\end{array}$ & UNB & 2000 \\
\hline 16 & $\begin{array}{l}\text { O enigma da esfinge - indefinição entre o } \\
\text { Publico e o privado: a relação dos conselheiros } \\
\text { Municipais de direitos (2000-2002) com o } \\
\text { Fundo Municipal dos Direitos da Criança e do } \\
\text { Adolescente de São Paulo }\end{array}$ & $\begin{array}{l}\text { Tatiana de Amorim } \\
\text { Maranhão Gomes } \\
\text { Silva }\end{array}$ & PUC - SP & 2003 \\
\hline 17 & $\begin{array}{l}\text { Rumo à democracia participativa: a travessia } \\
\text { Do Conselho dos Direitos da Criança e do } \\
\text { Adolescente }\end{array}$ & $\begin{array}{l}\text { Rodrigo Souza } \\
\text { Filho }\end{array}$ & UFRJ & 1996 \\
\hline 18 & $\begin{array}{l}\text { Conselhos e Fundos dos Direitos da Criança } \\
\text { E do Adolescente: uma opção pela democracia } \\
\text { Participativa }\end{array}$ & Denise Auad (tese) & USP & 2007 \\
\hline 19 & $\begin{array}{l}\text { O aprendizado da participação política: o } \\
\text { Conselho Municipal dos Direitos da Criança e } \\
\text { Do Adolescente - CMDCA/SP }\end{array}$ & Isis Souza Longo & USP & 2003 \\
\hline 20 & $\begin{array}{l}\text { Os Conselhos Municipais dos Direitos da } \\
\text { Criança e do Adolescente do Médio Vale do } \\
\text { Itajaí/SC: a agenda e seus organizadores }\end{array}$ & $\begin{array}{l}\text { Maria Salete da } \\
\text { Silva }\end{array}$ & UFSC & 2000 \\
\hline
\end{tabular}

